\title{
ANAEROBIC FERMENTATION OF COW MANURE AND WHEAT STRAW IN LOW VOLTAGE ELECTRIC FIELD
}

\author{
Imants Plume, Vilis Dubrovskis \\ Latvia University of Life Sciences and Technologies, Latvia \\ imants.plume@1lu.lv, vilisd@inbox.lv
}

\begin{abstract}
Anaerobic fermentation (AF) is widely implemented technology for energy and organic fertilizer production in more than 50 biogas plants in Latvia. Increasing the efficiency of the anaerobic fermentation process plays an important role in increasing the competitiveness of biogas plants and reducing the state financial support required for the operation of biogas plants. The use of a low-voltage electric field is a promising method for improving the AF process and biogas quality. Experimental investigation of low voltage (0.49-0.75 V) influence on the AF process of cow manure and wheat straw was provided in 16 laboratory bioreactors in volume of $0.75 \mathrm{~L}$ in batch mode at temperature $38^{\circ} \mathrm{C}$. The first group of 7 bioreactors was filled in with inoculums and cow manure and second group of bioreactors was filled in with inoculums and wheat straw. In each group, four bioreactors were arranged with graphite electrodes with wires for connection to a low voltage DC source. Biogas and methane obtainable from inoculums only were investigated in 2 control bioreactors for calculation of biogas obtainable from cow manure and wheat straw only. Anaerobic fermentation process was provided during 68 days until methane emission from bioreactors ceases. Both experimental groups showed an increase in methane production under the influence of a low-voltage electric field. The specific methane production from cow manure increases by $58 \%$, if $0.49 \mathrm{~V}$ DC electricity was supplied to bioreactors. The specific methane production from wheat straw decreases by $0.6 \%$, if $0.75 \mathrm{~V}$ DC electricity supplied to bioreactors in the second, post-fermentation period only. The effectiveness of usage of the electric field should be investigated further to optimise the electric voltage, form of electrodes and power supply mode.
\end{abstract}

Keywords: anaerobic digestion, methane, electro-microbial cell, manure, wheat straw.

\section{Introduction}

Biogas production is an environmental method to convert manure and agricultural by-products in energy and valuable organic fertiliser. Anaerobic fermentation (AF) of manure and following utilisation of methane also reduce methane emissions and global warming. Methane and nitrious oxide cause around $10 \%$ of greenhouse gas (GHG) emission in livestock production in the world [1].

Methane is considered as "powerful greenhouse gas, second only to carbon dioxide in its overall contribution to climate change. On a molecular level, methane is more powerful than carbon dioxide". "Methane emissions from livestock originate mainly from ruminant species (enteric fermentation) (80.7\%), manure management (17.4\%), and rice cultivation (1.2\%). Biogas from agricultural waste or residues can also cost-effectively mitigate methane emissions in the agriculture and the waste sectors. Conversely, biogas derived from food or feed crops increases methane emissions, and thus can undermine the mitigation benefits of biogas. It is therefore essential for biogas developments to be based primarily on waste or residues" [2].

Anaerobic fermentation of cattle manure as the only biomass source cannot be economically viable for middle or small farms, so co-fermentation of manure with agricultural by-products or wastes can be useful. Researchers have explored biomethane potential from different co-fermentation substrates with pre-treatment methods for straw including chopping, briquetting, thermal or chemical pre-treatment. Anaerobic co-digestion of cattle manure (CM) with shredded or briquetted wheat straw (SS and BS, respectively) was evaluated in thermophilic continuously stirred tank reactors (CSTR). Anaerobic digestion of CM, CM + SS and CM + BS in lab-scale reactors yielded 165; 214 and $2171_{\text {STP }}\left(\mathrm{CH}_{4}\right) \mathrm{kg}^{-1}$ (VS). Regarding the energy balance, the energy yields were the same for both reactors using straw as co-substrate after subtracting the energy consumption of the pre-treatment [3].

Another method used for improvement of fermentation of lignocellulosic biomass is thermochemical pre-treatment. Bioconversion of lignocellulose by microbial fermentation is typically preceded by an acidic thermochemical pretreatment step designed to facilitate enzymatic hydrolysis of cellulose. Substances formed during the pretreatment of the lignocellulosic feedstock inhibit enzymatic hydrolysis, as well as microbial fermentation steps [4].

It is needed to find new methods for improvement of the AF process of straw. Such a method can be use of the electric field for enhancement of the bioconversion process. Electro hydrolysis pre- 
treatment of pulp and paper mill sludge at $15 \mathrm{~V}$ for $45 \mathrm{~min}$ increased the methane production potential from $274 \pm 5$ to $301 \pm 4 \mathrm{~mL} \mathrm{CH}_{4} \cdot \mathrm{g}^{-1} \mathrm{VS}$ [5].

Another research deals with investigation of the effect of methane from maize silage substrate treated with a pulsed electric field with the following characteristics: voltage, $-40 \mathrm{kV}$; pulse duration $50 \mu \mathrm{s}$; frequency $-10 \mathrm{kHz}$; pulse shape, rectangular. The methane production rate for the control sample was $401.83 \mathrm{~mL} \mathrm{CH}{ }_{4} \cdot \mathrm{g}^{-1} \mathrm{VS}$ and it was $465.62 \mathrm{~mL} \mathrm{CH}_{4} \cdot \mathrm{g}^{-1} \mathrm{VS}$ for the sample following disintegration. The highest energy gain was obtained in the pre-treated sample at the retention time of $180 \mathrm{~s}$ $\left(0.235 \mathrm{Wh} \cdot \mathrm{g}^{-1} \mathrm{TS}\right)[6]$.

Next strategy is use of the electric field direct influence on microbial community in anaerobic fermentation (AF). The coupling of $\mathrm{AD}$ with microbial electrolysis cell systems aims to increase the yield and purity of methane. In this process, there are two routes to produce methane: (1) via electrochemistry, in which $\mathrm{CO}_{2}$ reacts with protons and electrons to be reduced to $\mathrm{CH}_{4}$, and (2) biologically by hydrogenotrophic microorganisms that improve the production rate and yield [7].

The effects of polarity and micro-voltage on anaerobic fermentation from lignocellulosic materials were investigated in a single-electrode fermenter to explore cost-efficient technology. The results illustrated that the biogas production and quality were significantly affected by the electric polarity. And cathode-assisted fermentation led to more positive effects than anode-assisted. Compared with the results in the control group without electrode, the average biogas and methane yields under cathodic micro-voltage $(-250 \mathrm{mV})$ were astonishingly improved by 2.82 and $2.44 \mathrm{~mL} \cdot \mathrm{g}^{-1} \cdot \mathrm{d}^{-1}$, respectively. Meanwhile, the degradation ratios of lignin and cellulose were also improved by $23.11 \%$ and $19.46 \%$ [8].

The methane fermentation study assisted with cathodic micro-voltage was carried out to investigate the electric field effects on fermentation of hydrothermally pretreated lignocellulose substrate. It was illustrated that a $0.25 \mathrm{~V}$ cathode voltage and hydrothermal pretreatment could improve the biogas production, biogas quality and lignocellulose degradation ratio significantly. In comparison with the fermentation pretreated at $200{ }^{\circ} \mathrm{C}$ without any voltage, nearly doubled of cumulative biogas production was obtained in the process of cathode- assisted fermentation. It was also observed that the daily methane content greater than or equal to $70 \%$ in the biogas generated with cathode voltage was clearly greater than that without voltages. Furthermore, the fermentation applied with a $0.25 \mathrm{~V}$ cathode voltage had resulted into significant increases of $12.64 \%$ and $9.44 \%$ in lignin and cellulose degradation ratio relative to voltage free fermentation [9].

Also, hydrogen gas can be produced by electrohydrogenesis in microbial electrolysis cells (MECs) at greater yields than fermentation and at greater energy efficiencies than water electrolysis. Through the use of a membrane-less system, a graphite fibre brush anode, and close electrode spacing, hydrogen production rates reached a maximum of $3.12 \pm 0.02 \mathrm{~m}^{3} \mathrm{H}_{2} \cdot \mathrm{m}^{-3}$ reactor per day $\left(292 \pm 1 \mathrm{~A} \cdot \mathrm{m}^{-3}\right)$ at an applied voltage of $E_{\mathrm{ap}}=0.8 \mathrm{~V}$. The energy efficiency relative to the electrical input decreased with applied voltage from $406 \pm 6 \%\left(E_{\mathrm{ap}}=0.3 \mathrm{~V}\right)$ to $194 \pm 2 \%\left(E_{\mathrm{ap}}=0.8 \mathrm{~V}\right)$. Overall energy efficiency relative to both $E_{\text {ap }}$ and energy of the substrate averaged $78 \pm 4 \%$, with a maximum of $86 \pm 2 \%$ $\left(1.02 \pm 0.05 \mathrm{~m}^{3} \mathrm{H}_{2} \cdot \mathrm{m}^{-3}\right.$ day, $\left.E_{\mathrm{ap}}=0.4 \mathrm{~V}\right)$. At $E_{\text {ap }}=0.2 \mathrm{~V}$, the hydrogen recovery substantially decreased, and methane concentrations increased from an average of $1.9 \pm 1.3 \%\left(E_{\text {ap }}=0.3-0.8 \mathrm{~V}\right)$ to $28 \pm 0 \%$ of the gas, due to the long cycle time of the reactor [10].

The influence of a low electric field on the co-fermentation process of manure with straw and paper dust $\mathrm{AF}$ was investigated in our previous research and showed the increase of methane production by $55.3 \%$ or $8.5 \%$ after the low voltage $0.60 \mathrm{~V}$ or $0.47 \mathrm{~V} \mathrm{DC}$ was applied to electrodes in microbial electrolysis cell (MEC) reactors with cow manure or paper dust, respectively [11].

The aim of the current study is to proceed an investigation of the anaerobic fermentation process of cow manure and wheat straw under the influence of a low voltage electric field in laboratory bioreactors.

\section{Materials and methods}

For microbial electrolysis experimental study, 16 round shaped bioreactors with the volume of $0.75 \mathrm{~L}$ were arranged with 3 anode and 3 cathode graphite electrodes. Every graphite electrode has dimensions 40x15x2 mm. All 6 electrodes were placed in the bioreactor in form of a circle with $60 \mathrm{~mm}$ inside diameter. 
All cathode and anode electrodes in the bioreactor were connected in parallel to increase the contact area and current density. The cathode and anode were connected to a low voltage $0.49-0.75 \mathrm{~V}$ DC power source, according to the experimental plan. Cow manure was obtained from farm "Mežacīrulil" just few days after the farm underwent the disinfestation process. No pre-treatment methods were applied to cow manure before anaerobic fermentation. Wheat straw was collected in the field in August during harvesting of cereals, and straw was crushed to obtain small particles in the length of $0.5-2.0 \mathrm{~mm}$ before anaerobic fermentation.

All components were analysed for total solids (TS) and dry organic matter (DOM) content before anaerobic fermentation to calculate the organic load rate in the bioreactor. Content of TS in the component samples was determined by drying the material in specialised equipment (type MOC-120H, accuracy $\pm 0.001 \mathrm{~g}$ ) at $105^{\circ} \mathrm{C}$. Dry organic matter content (DOM) was determined by aching of the samples in the oven (model Memmert) at $550{ }^{\circ} \mathrm{C}$ according to the standard aching cycle. Standard mathematical operations were used for calculation of total solids (TS) and volatile solids (VS) content.

The experiment involved 14 bioreactors that were divided in two groups with 7 bioreactors in each group. Low voltage $0.49 \mathrm{~V}$ or $0.75 \mathrm{~V} \mathrm{DC}$ was supplied to electrodes in microbial electrolysis cell reactors. 4 bioreactors were equipped with electrodes, while 3 bioreactors had no electrodes. The design and running of the experiments were based on the standard experimental methodical guide developed by German scientists [12]. All bioreactors were filled in with carefully mixed substrates and bioreactors were brought into the thermostat for the anaerobic fermentation (AF) process at temperature $38 \pm 0.5^{\circ} \mathrm{C}$. No organic material was added after the start of the anaerobic fermentation process.

Gases were collected in special gas bags 'Teadler' installed outside the thermostat. No additional material was added in reactors during the whole fermentation 68-day period, until gas emission ceases. The gas volume was measured by a flow meter (Ritter drum-type) and the gas (methane, hydrogen) composition was measured by help of a specialised gas analyser (model Gasboard 3200L). Substrate $\mathrm{pH}$ value was measured in the bioreactor before and after the AF process using a $\mathrm{pH}$ meter (model HI 8424, accuracy \pm 0.01 ). The substrate weight before and after the AF cycle was determined by scales (type $\mathrm{KFB} 16 \mathrm{KO}$, accuracy $\pm 0.2 \mathrm{~g}$ ). Electric parameters (voltage and current) were measured using a multimeter (model FLUKE AUTO-V Lo2).

The fermentation cycle was virtually divided in 2 periods, the first lasts for 40-days and the second one lasts for 28-days, after that gas emission ceases. After the gas release ceases, all the substrates were weighted and total solids and dry organic matter content were determined using known methods and standard mathematical operations. Average biogas, methane and hydrogen volumes obtained from the control reactors (with inoculums only) were subtracted from biogas and methane volumes from bioreactors with added biomass, to calculate the biogas and methane volumes from added biomass. The energy balance of usage of the electric field for AF was determined by the energy consumed (current and voltage during anaerobic fermentation) to the energy obtained (the lower heating value for surplus methane).

\section{Results and discussion}

Composition of substrates, weight and content of organic matter in substrates before anaerobic digestion within the first experiment are shown in Table 1.

Table 1

Results of analyses of components and substrates before anaerobic fermentation

\begin{tabular}{|c|c|c|c|c|c|c|}
\hline Bioreactors & Components, g & Weight, $\mathbf{g}$ & DM, g & DM, \% & VS, g & VS, \% \\
\hline R1; R16 & IN500 & 500 & 16.96 & 3.39 & 12.29 & 2.46 \\
\hline Added biomass & CM20 & 20 & 3.90 & 19.48 & 3.59 & 17.51 \\
\hline Added biomass & WS12 & 12 & 10.57 & 88.12 & 10.06 & 83.79 \\
\hline R2-R5; R10-R12 & IN500 + CM20 & 520 & 20.86 & 4.01 & 15.88 & 3.05 \\
\hline R13-R15 & IN500 + WS12 & 512 & 27.53 & 5.38 & 22.35 & 4.37 \\
\hline
\end{tabular}

Note: IN-inoculums; CM-cow manure; WS - wheat straw; DM-dry matter; DM\% - percentage of dry matter in component or substrate; VS - volatile solids (organic matter); VS\% - percentage of 
volatile solids in biomass; R1; R16-bioreactors with inoculums (control); R2-R5 - group of bioreactors with similar substrates containing inoculums and added biomass

Raw substrate analyses show that wheat straw (WS) biomass has higher organic matter content compared to cow manure (CM) at the start of anaerobic fermentation.

Average specific methane yield from different groups of bioreactors is shown in Fig. 1.

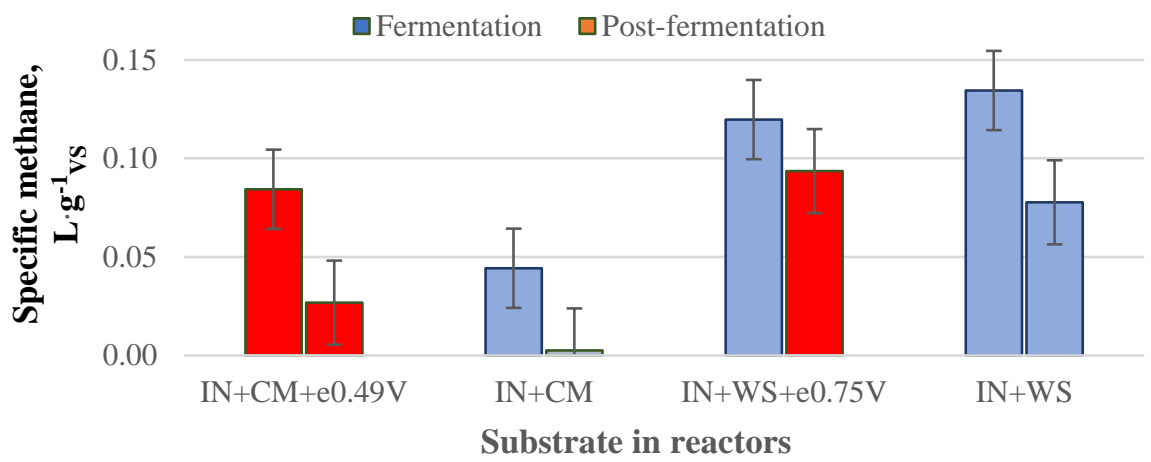

Fig. 1. Average specific methane volume for groups of bioreactors: IN - inoculums; CM - cow manure; WS - wheat straw; fermentation - 40-days period of fermentation (left column); postfermentation - 28-days period of post-fermentation (right column); e - electrodes installed in bioreactor; $0.49 \mathrm{~V}-\mathrm{DC}$ voltage of $0.49 \mathrm{~V}$ applied in fermentation and post-fermentation period; $0 / 0.75 \mathrm{~V}-\mathrm{DC}$ voltage of $0.75 \mathrm{~V}$ applied in post-fermentation period only;

blue coloured bar area - DC voltage $0.49 \mathrm{~V}$ or $0.74 \mathrm{~V}$ switched OFF; red coloured bar area $-\mathrm{DC}$ voltage $0.49 \mathrm{~V}$ or $0.74 \mathrm{~V}$ switched $\mathrm{ON}$

The experimental results show high increase in the average specific methane yield from bioreactors with cow manure in fermentation or post-fermentation periods by 47.5 or $90.5 \%$, respectively, if the low voltage $0.49 \mathrm{~V}$ was applied to electrodes in bioreactors. Average specific methane volume from bioreactors with cow manure and voltage $0.49 \mathrm{~V}$ applied to electrodes during both fermentation periods was $0.111 \mathrm{~L} \cdot \mathrm{g}^{-1} \mathrm{vs}$, or by $57.9 \%$ higher compared to reactors without electrodes.

Specific average methane volume released from wheat straw in the first fermentation process from bioreactors with (WS) arranged with electrodes, and with DC voltage switched OFF was by $12.3 \%$ less, compared to bioreactors without electrodes. The reason for such lowering of specific methane can be explained by some inhibiting effect of graphite electrodes inserted in substrate without applied voltage. Specific average methane volume released from wheat straw in the post-fermentation process from bioreactors with electrodes, and with DC voltage $0.75 \mathrm{~V}$ switched ON was higher by $17 \%$, compared to bioreactors without electrodes. Total specific methane yield from bioreactors with wheat straw and voltage switched OFF in the first period and voltage $0.75 \mathrm{~V}$ switched $\mathrm{ON}$ to electrodes during the postfermentation period was $0.213 \mathrm{~L} \cdot \mathrm{g}^{-1} \mathrm{vs}$, or by $0.5 \%$ higher compared to reactors without electrodes. The experimental data show that higher biogas and methane yields were obtained from wheat straw compared to cow manure. It may be explained by the lower organic matter content in manure compared to wheat straw, see Table 1. Also, the manure was collected in a dairy cow farm in the period of disinfection of the farm facilities, so disinfectants may inhibit the AF process in the reactors containing cow manure.

The obtained specific methane volume and methane content in biogas from wheat straw were lower compared to earlier experimental research on wheat straw AF process [11]. It may be explained by higher electric resistance of substrates providing lower current in substrates compared to current in the previous experiment.

Specific hydrogen volumes per gram of initial volatile solids of added biomass from bioreactors with and without a low voltage electric field applied are given in Fig. 2.

The experiment results show an increase of average specific hydrogen volumes by $38.0 \%$, if the low electric field of $0.49 \mathrm{~V}$ was applied to substrates with cow manure during both periods of the fermentation process. 
Average specific hydrogen volume increases by $17.0 \%$, if the electrodes in WS substrates were connected to a voltage $0.75 \mathrm{~V} \mathrm{DC}$ source during the post-fermentation period. Average specific hydrogen volume from bioreactors with cow manure and voltage $0.49 \mathrm{~V}$ applied to electrodes during both fermentation periods was $0.01 \mathrm{~L} \cdot \mathrm{g}^{-1} \mathrm{vs}$, or by $0.5 \%$ lower compared to reactors without electrodes.

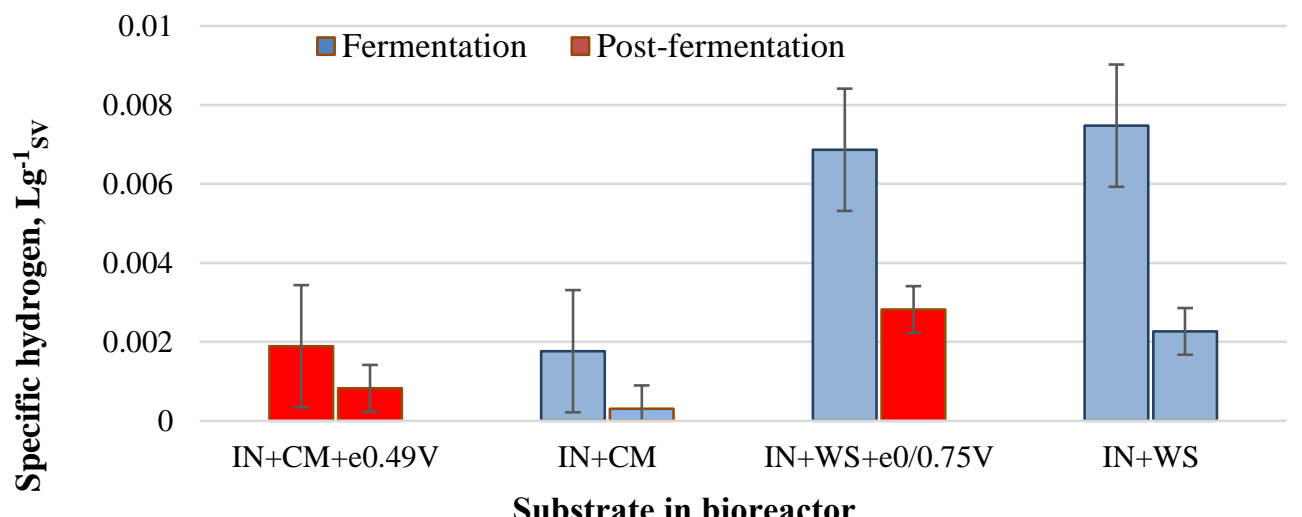

Fig. 2. Average specific hydrogen volume for groups of bioreactors: IN - inoculums; CM - cow manure; WS - wheat straw; fermentation - 40-days period of fermentation (left column); postfermentation - 28-days period of post-fermentation (right column); e - electrodes installed in bioreactor; $0.49 \mathrm{~V}-\mathrm{DC}$ voltage of $0.49 \mathrm{~V}$ applied in fermentation and post-fermentation period;

$0 / 0.75 \mathrm{~V}-\mathrm{DC}$ voltage of $0.75 \mathrm{~V}$ applied in post-fermentation period only;

blue coloured bar area - DC voltage $0.49 \mathrm{~V}$ or $0.74 \mathrm{~V}$ switched OFF; red coloured bar area - DC voltage $0.49 \mathrm{~V}$ or $0.74 \mathrm{~V}$ switched $\mathrm{ON}$

Average voltage, current and power measured for each of bioreactors R3-R5 was $0.49 \mathrm{~V}, 0.11 \mathrm{~mA}$ and 5.03E-05 W, and the same values measured for each of bioreactors R7-R9 was $0.75 \mathrm{~V}, 0.01 \mathrm{~mA}$ and $9.72 \mathrm{E}-06 \mathrm{~W}$. The low average current value in bioreactors with wheat straw may be regarded as the main reason for small effect of the electrical field on the specific methane yield from these reactors. Energy balance for the low voltage electric field use was positive, as surplus methane energy compared to the electric energy consumed was 27 or 5 times higher for cow manure or wheat straw fermentation, respectively.

\section{Conclusions}

1. The results show high increase in the average specific methane yield by 47.5 or $90.5 \%$ from bioreactors with cow manure in the first 40-day fermentation or the second 28-day postfermentation period respectively, if the low voltage $0.49 \mathrm{~V}$ was applied in bioreactors.

2. The total average specific methane yield from bioreactors with cow manure under the influence of the low voltage $0.49 \mathrm{~V}$ electric field was by $58.0 \%$ higher compared to the methane yield from bioreactors without voltage.

3. Specific average methane volume released from wheat straw in the post-fermentation process from bioreactors with electrodes with DC voltage $0.75 \mathrm{~V}$ was higher by $17 \%$, compared to bioreactors without electrodes.

4. The experiment shows an increase of the average specific hydrogen volumes by $38.0 \%$, if the low electric field of $0.49 \mathrm{~V}$ was applied to substrates with cow manure.

5. The average specific hydrogen volume increases by $17.0 \%$, if the electrodes in wheat straw substrates were connected to the voltage $0.75 \mathrm{~V}$ DC source during the second period of fermentation.

6. Energy balance for low voltage electric field use was positive, as surplus methane energy compared to the electric energy consumed was 27 or 5 times higher for fermentation of cow manure or wheat straw, respectively.

7. The effectiveness of usage of the electric field for the AF process should be further investigated for optimization of the power supply mode, electric voltage, various forms of electrode usage in different substrates. 


\section{Acknowledgements}

The research was supported by a grant from the Latvia University of Life Sciences and Technologies for the internal project "Studies on the effectiveness of the anaerobic fermentation process of biomass", theme G4.

\section{References}

[1] Grossi G., Goglio P., Vitali A., Williams A.G. Livestock and climate change: impact of livestock on climate and mitigation strategies. Animal Frontiers, vol. 9(1), 2019, pp. 69-76.

[2] European Commission. On an EU strategy to reduce methane emissions, Brussels, 14.10.2020 $\operatorname{COM}(2020) 663$ final, $21 \mathrm{p}$.

[3] Xavier C.A., Moset V., Wahid R., Møller H. B. The efficiency of shredded and briquetted wheat straw in anaerobic co-digestion with dairy cattle manure. Biosystems Engineering, vol. 139, 2015, pp. 16-24.

[4] Jönsson L.J., Bjorn A., Nilvebrant N.O. Bioconversion of lignocellulose: inhibitors and detoxification. Biotechnology for Biofuels, vol. 6-16, 2013, $10 \mathrm{p}$.

[5] Veluchamy C., Wilson Raju V., Ajay S.Kalamdhad A.S., Prerequisite - An electrohydrolysis pretreatment for anaerobic digestion of lignocellulose waste material. Bioresource Technology, vol. 235, 2017, pp. 274-28.

[6] Szwarc D., Szwarc C. Use of a Pulsed Electric Field to Improve the Biogas Potential of Maize Silage. Energies, vol. 14 (119), 2021, 10 p.

[7] Buitrón G., Cardeña R., Arcila J.S. Chapter 5.9 - Bioelectrosynthesis of Methane Integrated With Anaerobic Digestion. In Biomass, Biofuels and Biochemicals, Microbial Electrochemical Technology, 2019, pp. 899-919.

[8] Qu G., Qiu W., Liu J., Zhong D., Ning P. Electropolar effects on anaerobic fermentation of lignocellulosic materials in novel single-electrode cells. Bioresource Technology, vol. 159, 2014, pp. 88-94.

[9] Liu D., Ning P., Qu G., Huang X., Liu Y., Zhang J. The effects of cathodic micro-voltage combined with hydrothermal pretreatment on methane fermentation of lignocellulose substrate. IOP Conf. Ser.: Earth Environ. 64 2017. 10 p.

[10] Call D., Logan B. Hydrogen Production in a Single Chamber Microbial Electrolysis Cell lacking a membrane. Environ. Sci. Technol. 42 (9), 2008, pp. 3401-3406.

[11] Plume I., Dubrovskis D. Effectiveness of low voltage electric field usage for anaerobic fermentation of manure, straw and paper dust. Proceedings of 19th International scientific conference "Engineering for rural development", proceedings, Latvia University of Life Sciences and Technologies, Jelgava, 2020, vol. 19, pp. 1907-1913.

[12] Kaltschmitt M. Methodenhandbuch (Method manual), Leipzig, 2010, 93 p. (In German). 